\title{
COMPTE RENDU/BOOK REVIEW: Noëlle à Cuba: Un Roman de la modernité
}

Pierre Karch vient de nous donner avec Noëlle à Cuba (Prise de Parole, 1988, 392 p.) un excellent roman, pas comme les autres. Certes, c'est un roman plein de romanesque; de plus, bien d'actualité. Un groupe de touristes canadiens s'en va chercher le soleil et l'oubli de ses petites misères quotidiennes au soleil de Cuba, pendant les vancances de Noël. Titre ambigu donc, ressort poétique, c'est le Noël de Noëlle - naissance à l'amour d'une petite employée montréalaise. En fait, ce n'est pas elle l'héroïne du roman, emportée dans le tourbillon des touristes qui perdent la tête sous l'effet des vacances, comme d'autres dans la drogue ou l'alcool. Le rhum cubain va bien aider d'ailleurs à créer cet unanimisme dont parlait Jules Romain et qui fera l'originalité première de ce roman, histoire d'un groupe plutôt que d'un personnage central.

N'allez donc pas chercher dans ce livre plein de verve et d'aventures, cocasses ou tristes, la structuration d'un roman classique. Pas de noeud d'intrigue autour de Noëlle, de drame dont elle ferait les frais du début à la fin. Elle apparaît, disparaît, on la perd souvent, ne réapparaît que lorsqu'on a commencé à l'oublier pour ne la retrouver parfois qu'à travers les réactions d'autres personnages. On est souvent, de ce point de vue, plongé dans une atmosphère à la Henry James. Et l'on s'aperçoit vite que ce qui intéresse le romancier ce n'est pas un cas particulier mais les mille petites tragédies individuelles de la vie de tous ses personnages. Pierre Karch serait-il cet esthète - un romancier qui suit de près ses personnages et commente sa propre existence en même temps que celles qu'il décrit - et à qui il prête ces paroles : "Les critiques s'accordaient pour dire qu'il faisait son plat principal de ce qui passait inaperçu aux autres, ce qui revenait à dire qu'il excellait dans la finesse et la justesse des descriptions de détails"?

Mais ce qui pourrait paraître alors une faiblesse du roman devient sa force, grâce à la technique utilisée, celle des "clips". Pierre Karch procède, en effet, par éclairages fulgurants. Aussi bien au plan du contenu que de l'expression, les notations sont brèves et colorées. On n'a jamais le temps de s'ennuyer et l'auteur sait passer alternativement de la note triste ou mystérieuse à la note gaie voire hilarante. La belle Daphné perd sa virginité et ses illusions, la

LittéRéalité, Vol. I, No. 1, Printemps/Spring 1989 
veuve noire inquiète, la chasse aux tableaux de Morrice finit de façon cruelle et tragi-comique, Roland meurt écrasé alors qu'on attendait la mort de sa femme, des amours se font et se défont, les uns s'ennuient ferme et les autres font semblant de s'amuser. Le tragique des situations rocambolesques de ce microcosme débridé trouve l'une de ses plus belles illustrations, vers la fin du livre, dans la rencontre pathétique d'une petite vieille et d'un des touristes en qui elle croit et veut de toutes ses forces reconnaître Santiago, un jeune homme dont elle a été amoureuse toute petite fille.

Pierre Karch a peint là, de main de maître, une étonnante galerie de portraits. Noëlle, d'abord, la timide frustrée qui se révèlera dans un éclat de passion final; Énid, qui écrit des contes sans intérêt et dont elle inflige la lecture aux autres; Liljana, la belle aventurière qui ne peut s'empêcher de séduire et de raconter ses bonnes fortunes; Daphnée la mal mariée; Sophie, l'alcoolique; Ana, la peintre; Mariposa, la petite Cubaine, adolescente trouble, légère et jolie comme les papillons qui tournent toujours autour d'elle; Marco, le beau garçon sans scrupule; Chango, le méchant qui veut se venger; et puis une foule d'autres personnages dont Icare, le don Juan. C'est à mon avis le personnage central -- un don Juan beau garçon mais qui fait peu la cour. Il intrigue par ses airs de grand seigneur indifférent et sa façon de parler ironique et poétique. Il tourne toutes les têtes et vole d'une conquête à l'autre, plutôt séduit que séducteur.

Ce regard sur le monde, tantôt amusé, tantôt désabusé, Pierre Karch le décrit avec beaucoup de finesse d'obervation, d'humour, de sensualité et une grande maîtrise dans l'écriture.

Voici, par exemple le portrait de la gourmande : "Eurydice avait été la première à pénétrer dans la salle à manger et, à l'heure qu'il était, on aurait pu croire qu'elle venait de s'y installer tant étaient hautes les montagnes de fruits, de pains, de crêpes et de petits gâteaux qu'elle avait savamment disposés sur sa table, devant elle, selon un art qui n'appartient qu'à quelques maîtres d'hôtel, héritiers des vieilles traditions. On aurait dit que, depuis qu'elle avait mis au monde Rombaut, le dernier et le plus malingre de ses enfants, elle mangeait pour elle et pour lui et pour tous ceux qui avaient faim. Consciente qu'elle n'arriverait jamais au bout de sa faim, elle en avait pris son parti et adopté la conduite qui convenait le mieux à sa condition : comme les baleines qui se nourrissent de plancton, elle mangeait toute la journée mais ne prenait que de toutes petites bouchées qu'elle promenait longtemps dans sa bouche avant de les avaler". On trouvera aussi, à côté de la vision 
romanesque, le regard précis, caustique ou attendri du journaliste, lorsqu'il s'agit de Cuba, ses églises, ses marchés, son air à la fois austère et coloré.

L'humour est partout, dans la réflexion comme dans la description. La plume de Pierre Karch griffe ainsi au passage, mais sans méchanceté, les travers humains, les amours, la politique, les écrivains, la religion. "Ana se dit qu'il est parfois aussi difficile d'éviter certains sujets que de sortir d'un mauvais lieu sans croiser quelqu'un de connaissance"... "Les tarots, les boules de cristal et les horoscopes, tout ce monde qui hésite entre le naturel et ce qui ne l'est pas, lui faisait un peu peur, comme les douanes, Revenu Canada et l'informatique"... "Comme un Pape, un astrologue qui dirait tout n'aurait plus rien à dire"... "Je ne te promets pas le ciel, lui dit-il dans un sourire plein de perversité, mais si tu es bonne fille, je te ferai voir le Vatican".

Pierre Karch possède un art très gidien de faire sentir la moindre sensation, d'en faire partager le côte palpable. À Cuba, "cette moiteur, on l'accueille comme une caresse trop intime pour se plaindre"... "C'était si facile le bonheur : un peu d'eau fraîche, un rayon de soleil, une main qui se pose sur la sienne et efface la douleur". Souvent, la sensualité se mélange d'un délicieux humour, comme dans cette finale amoureuses: "les nuits de cette qualité, Dieu les destine au sommeil mais le diable, qui s'en mêle toujours un peu, les voue à l'amour".

Chose rare de nos jours, Pierre Karch écrit bien. Sa technique des clips nous rappelle l'impressionnisme, le style artiste d'un Huÿsmans ou des Goncourt, fait de contrastes, de raccourcis saisissants, comme ; " Il avait voulu être son amant de droit divin et elle l'avait trouvé divin amant"..."Je t'ai apporté une orange, dit-elle pour le distraire, et c'était son coeur qu'elle lui offrait"...

À l'antithèse, se joint joliment l'ellipse et l'euphémisme: "Elle était belle, plus encore que la veille, et il le lui prouva". Cette sorte de préciosité est souvent compensée par une chute que n'auraient désavouée ni La Fontaine, ni La Bruyère, ni La Rochefoucauld : "Il ne peut y avoir de bonheur sans souvenirs"... "Qu'il faut peu d'applaudissements pour encourager un auteur"... "Or, sur sa branche, une fleur se croit toujours immortelle, comme nous".

Ce roman nous entraîne à un rythme tout moderne de découpage rapide, aussi bien pour l'histoire que pour la manière dont elle est exprimée. Mais, à ce double plan, il est ponctué, d'une part par la narration d'un romancier dans le roman et, d'autre part, de passages où la phrase se fait ample et poétique. C'est un art de la respiration dans le texte, savamment mis au point. 
La narration du romancier, réflexion méta-romanesque, est souvent teintée là encore d'une pointe d'humour : "Un écrivain doit puiser son encre en luimême". S'il arrive à l'écrivain désabusé de regretter ne pas avoir le souffle des Martin du Gard, il retrouve la veine qu'il affectionne lorsqu'il se surprend à décrire, un peu à la manière de Ponge, les coquillages qu'il a déposés sur son bureau. Après ce passage, qui est un petit chef-d'oeuvre par la précision d'orfèvre de la description, une jolie pirouette amène la conclusion : "Ce que le journal taisait, c'était le nombre de coquillages qu'il avait rejetés, faute de mots pour les dire".

Quant aux respirations phrastiques du texte, il en est de fort jolies, où l'on reconnaîtra, ça et là quelques alexandrins ou octosyllabes, pudiquement cachés dans une prose très poétique. "Ce n'était pas le tonnerre, c'était la mer. On dit que les dieux païens se sont tus, mais se pourrait-il que du fond des eaux, Aphrodite, émue par la danse que Daphné avait exécutée pour elle, venait l'en remercier et châtier l'homme qui l'avait offensée?".... Et le romancier qui cherche comment décrire la plage va noter: "Il lui aurait fallu une phrase qui s'étende jusqu'à l'horizon où la mer sans vague traçait une ligne de la même encre que le ciel".

On voit que Noëlle à Cuba a, par son écriture, encore bien des côtés d'un beau classicisme. Mais son originalité est indéniable. C'est un roman jeune par l'action et sa présentation. Probablement l'un des premiers vrais romans de la modernité.

Pierre Léon (University of Toronto) 